\title{
Two Senses of Moral Verdict and Moral Overridingness
}

\author{
PAUL HURLEY
}

\section{SECTION I: INTRODUCTION}

In what follows I distinguish two different senses in which philosophers speak of moral verdicts, senses that in turn invite two different senses of moral overridingness. Although one of these senses of moral verdict currently dominates the moral overridingness debate, I focus primarily on the other, and on the importance of disambiguating the two. In section II I show that it is this other sense that offers the most straightforward explanation of the apparent conceptual connections between moral verdicts and both reasons and reactive attitudes. I demonstrate in section III that it is also the central sense deployed by moral theories that recognize distinctively moral reasons, but that need not appeal to distinctive moral verdicts from a distinctively moral point of view. In section IV I show that as more sophisticated variants have been developed within the dominant sense of moral verdict they have come to deploy central elements of this alternative sense, bringing the two closer together. I suggest along the way that the recent tendency to emphasize the dominant sense to the exclusion of the alternative, coupled with the failure to properly disambiguate the two, has fundamentally skewed central debates in moral theory. Finally, in section V I sketch a proposal for understanding the relationship between these two distinct senses.

One standard presentation of the overridingness debate provides a particularly useful vehicle for distinguishing these two different senses of moral verdicts and moral overridingness. The defense of overridingness, on this standard approach, typically involves arguments for something like the following two claims:

Claim 1: Agents are morally required to perform certain actions. 
Claim 2: If agents are morally required to perform certain actions, then they have decisive reasons that are in some sense distinctively moral to perform such actions. ${ }^{1}$

Consider first the conditional, Claim 2. Many philosophers take this claim to capture a conceptual truth about moral verdicts. ${ }^{2}$ Others take it to be a substantive claim, and many of these philosophers take this substantive claim to be false. ${ }^{3}$ How can one and the same claim strike so many philosophers working on moral verdicts and overridingness as a conceptual truth, and strike so many others as a substantive claim that is pretty clearly false? The explanation of this striking divergence, I suggest, is that philosophers in these two groups are appealing to very different senses of moral verdict, in this case of moral requirement.

The first sense takes such moral verdicts to reflect decisive reasons for acting from a distinctively moral standpoint, viewpoint, or point of view. ${ }^{4}$ The second sense takes moral verdicts to reflect decisive reasons

1 The locus classicus of this traditional characterization of moral overridingness is Philippa Foot's “Are Moral Considerations Overriding?" in Virtues and Vices (Los Angeles: University of California Press, 1978), pp. 181-8. She characterizes this as "verdictive" rather than "evidential" moral overridingness. There are myriad defenses and criticisms in the literature of claims in the neighborhood of Claim 2. See for example Michael Smith, The Moral Problem (Oxford: Blackwell, 1984), p. 65; Douglas Portmore, Commonsense Consequentialism (New York: Oxford University Press, 2011), p. 28: "MR: If a subject, S, is morally required to perform an act, $\mathrm{x}$, then $S$ has most (indeed, decisive) reason to perform x, all things considered"; and Alfred Archer, "Moral Rationalism Without Overridingness," Ratio 27 (2014): 100-14, particularly his characterizations of weak overridingness and moral rationalism (pp. 104-5). I will follow Foot's initial characterization of claims such as Claim 2 as "verdictive" rather than "evidential" moral overridingness claims.

2 See, for example, Smith, The Moral Problem, p. 64, and Stephen Darwall, The SecondPerson Standpoint (Cambridge, MA: Harvard University Press, 2006), p. 94. See section III for a fuller discussion.

3 This is the position defended, for example, by Foot herself ("Are Moral Considerations Overriding?"), and more recently by philosophers such as Dale Dorsey ("Weak AntiRationalism and the Demands of Morality," Nồs (March 2012): 1-23).

${ }^{4}$ Such talk of moral, prudential, aesthetic, etc. standpoints or points of view pervades contemporary normative ethics, but what commitments are involved in such talk is often as obscure as such appeals are pervasive. A characteristic feature of virtually all such accounts, however, is that they issue distinctively moral verdicts from such distinctively moral points of view. This aspect of all such accounts raises the separate question as to what the relationship is between such moral verdicts from a distinctively moral point of view and the reasons simpliciter that agents have to act. It is this shared feature of such accounts that is central to the arguments that follow. 
simpliciter $^{5}$ for acting that are in some sense distinctively moral. ${ }^{6}$ Because the first sense invokes decisive reasons from a distinctively moral standpoint, I will refer to it in what follows as the moral standpoint sense, and to the resulting verdicts as moral standpoint moral verdicts. Because the second sense invokes decisive reasons simpliciter that are in some sense distinctively moral, I will refer to it as the rational standpoint sense, and to such verdicts as rational standpoint moral verdicts. To claim that we are rational standpoint morally required to perform actions of a certain type, e.g., to keep our promises, is to claim that we have decisive reasons simpliciter to keep our promises that are in some sense distinctively moral, at least ceterus paribus. It is to claim that we ought to keep our promises in the standard decisive reasons sense of ought, and that the reasons why we should do so are in some sense distinctively moral reasons. To claim that we are moral standpoint morally required to perform actions of a certain type, e.g., to promote the overall good, is to claim that we have decisive reasons to promote the overall good from a distinctively moral point of view. Such a verdict leaves open the question of what relationship there is between such decisive reasons from a distinctively moral point of view and the agent's reasons simpliciter to act. Do we have reasons simpliciter to do what is moral standpoint morally required, and if so, are such reasons simpliciter decisive with respect to other reasons, reasons that may themselves be distinctively prudential or aesthetic? On the rational standpoint sense, claims of moral requirement are claims of rational requirement simpliciter. On this moral standpoint sense, claims of moral requirement are claims of rational requirement from a distinctively moral point of view, claims that leave unspecified the relationship between rational requirement from a distinctively moral point of view and rational requirement simpliciter.

Such distinct senses readily account for the striking divergence in understandings of Claim 2. For those deploying the rational standpoint

\footnotetext{
5 In this paper I bracket skeptical challenges to the standard view that there are reasons simpliciter, for example the challenge offered by David Copp in "The Ring of Gyges: Overridingness and the Unity of Practical Reason," in Morality in a Natural World (Cambridge: Cambridge University Press, 2007), pp. 284-308.

${ }^{6}$ Notice that I stop short in this formulation of identifying moral requirement with decisive reasons simpliciter that are distinctively moral. This is in part to accommodate views such as Stephen Darwall's, upon which such decisive distinctively moral reasons are a necessary but not a sufficient condition for moral obligation, hence for moral requirement.
} 
sense, moral requirements are rational standpoint moral verdicts, reflecting decisive reasons simpliciter for acting that are in some sense distinctively moral. Claim 2 is, on this rational standpoint understanding, a conceptual truth that merely makes explicit one aspect of what it is for some action to be morally required. For those deploying the moral standpoint sense, by contrast, moral requirements are moral standpoint moral verdicts, reflecting only decisive reasons for acting from a distinctively moral standpoint, viewpoint, or point of view. Claim 2 is on such a moral standpoint understanding a substantive claim about the relationship between decisive reasons from the distinctively moral point of view and decisive reasons simpliciter. If agents sometimes do not have decisive reasons simpliciter to do what they have decisive reasons to do from the distinctively moral point of view, then this substantive claim will be false.

Our two claims also provide a useful tool for isolating the two very different questions of moral overridingness invoked by these two different senses of moral verdict. Operating with the moral standpoint sense the moral standpoint overridingness question is, quite simply, the question of whether Claim 2 is true. Claim 1 is typically granted by those who adopt this sense. That is, it is typically granted that there are moral verdicts reflecting decisive reasons from a distinctively moral point of view. The question is whether it is always (typically?) true that if agents are moral standpoint morally required to perform these actions or types of actions, they have decisive reasons simpliciter that are distinctively moral to do so (Foot's Verdictive Moral Requirements). If so, morality is moral standpoint overriding; if not, it is not.

For those operating within the rational standpoint sense, by contrast, Claim 2 is trivially true-if agents are morally required to perform certain actions, this is just to say, in part, that they have decisive reasons that are in some sense distinctively moral to perform them. The question of rational standpoint overridingness is instead whether, given the truth of Claim 2, Claim 1 is itself true. Are there acts or act types which rational agents have overriding reasons that are distinctively moral to perform, at least ceterus paribus? Michael Smith offers an analogy with witches to clarify the overridingness question within this rational standpoint sense of moral verdicts. It is a conceptual claim (at least let's allow this) that witches have supernatural powers; it is a substantive claim whether there are any witches, and if so, who they are and what might be the nature of their powers. Similarly, it is a conceptual claim that rational standpoint 
moral verdicts provide agents with decisive reasons simpliciter to act, but it is a substantive claim whether there are such rational standpoint moral verdicts-whether and when agents in fact have overriding reasons that are distinctively moral. ${ }^{7}$ Rational standpoint overridingness concerns the truth of this latter, substantive claim.

It is instructive to consider the implications of disambiguating these distinct senses for Peter Singer's influential argument that the more affluent are morally required to spend themselves down to subsistence to alleviate poverty - that it is morally wrong not to do so. Is the result of this argument a moral standpoint moral requirement, claiming only that there are decisive reasons to do so from a distinctively moral point of view, or is it a rational standpoint moral requirement, claiming that agents have decisive reasons that are distinctively moral to do so?

Singer initially seems clearly to be invoking the moral standpoint sense, rendering a verdict that only takes into account other considerations "comparable in moral significance" (emphasis mine). Such verdicts that result from taking into account only distinctively moral considerations, the considerations relevant from a distinctively moral point of view, will yield only moral standpoint moral verdicts. But the qualifier "moral" disappears in the conclusion of Singer's argumentsuch sacrifice, Singer concludes, "is something that everyone ought to do." This "ought" simpliciter suggests that the argument establishes decisive reasons simpliciter that are distinctively moral, a rational standpoint moral verdict.

But later in Practical Ethics Singer is clear that it does not. The conclusion establishes at most "what we ought, morally, to do," a moral standpoint moral requirement from "a standpoint like that of the impartial spectator. ${ }^{10} \mathrm{He}$ is also clear that he has not demonstrated

\footnotetext{
7 Smith, The Moral Problem, p. 64. Darwall draws a similar distinction, arguing that even if it is a "conceptual matter" that "genuine moral oughts would provide... reasons that are conclusive for all agents... it might be that no putative moral ought actually provides these reasons" (Stephen Darwall, "Morality and Practical Reason," in The Oxford Handbook of Ethical Theory, ed. David Copp (New York: Oxford University Press, 2006), p. 283). Whether there are such moral oughts that actually provide these reasons is the question, for those operating within the rational standpoint sense, of whether Claim 1 is true. This is the question of rational standpoint overridingness.

8 Peter Singer, Practical Ethics (Cambridge: Cambridge University Press, 1979), p. 169.

9 Singer, Practical Ethics, p. 169.

10 Singer, Practical Ethics, pp. 201 and 204 respectively.
} 
that rational agents ought simpliciter to spend down to subsistence, in the decisive reasons implying sense of ought that is "simply... a way of asking for reasons for action without any specification about the kinds of reasons wanted." ${ }^{11}$ Such an argument would require the additional demonstration of "a link between reason and ethics," but Singer takes all such attempts to have failed. Indeed, because he endorses the "Humean" view that "reason in action applies only to means, not ends," and that such ends "must be given by our wants and desires," 12 his view suggests that whether a given agent has any reason, much less decisive reasons, to do what is moral standpoint morally required is entirely a function of the relative strengths of that agent's aesthetic, prudential, ethical, and other desires.

Often those who deploy the moral standpoint sense of moral verdict are happy to allow that moral standpoint moral requirements are reflected in strong reasons simpliciter that are distinctively moral. Decisive reasons from a distinctively moral point of view, they allow, are typically reflected in strong reasons simpliciter. But the tendency to conflate the two senses of moral verdict can obscure the need for those deploying this moral standpoint sense to provide a substantial account of the relationship between decisive reasons from the distinctively moral point of view and reasons simpliciter. The need is particularly pressing in cases, such as those of Singer and many other traditional consequentialists, in which what is taken to be moral standpoint morally required far exceeds what commonsense suggests that we have decisive reasons simpliciter to do. Singer, we have seen, not only does not purport to demonstrate that his moral standpoint moral requirements are typically reflected in decisive reasons simpliciter, he takes the most plausible account of reason to stand in the way of providing such an account. Bernard Williams goes a step further, arguing that traditional act consequentialist theories are structurally incapable of providing such an account. He makes the case that in their very determination of impersonal moral

11 Singer, Practical Ethics, p. 203.

12 Singer, Practical Ethics, p. 207. But see Singer's more recent work (with Katarzyna De Lazari-Radek, The Point of View of the Universe (Oxford: Oxford University Press, 2014)) in which he abandons such Humeanism about reason to go where even Henry Sidgwick feared to tread, arguing that the moral point of view, understood as the point of view of the impartial spectator, is the rational point of view. On such an account whatever actions are moral standpoint morally required are, trivially, rational standpoint morally required. 
requirements, such consequentialists deploy an account of practical reason and deliberation upon which the reasons agents have to conform to such moral requirements are but some reasons among others. These other reasons, he suggests, often seem sufficient for the agent not to do what morality requires. Reason, as such consequentialists must understand it, alienates rational agents from their own standards of moral standpoint moral requirement. ${ }^{13}$ At the very least, Williams' arguments demonstrate that those working within the moral standpoint sense cannot simply help themselves to the rational authority of their moral standpoint moral requirements. Such authority must be earned through argument; Williams makes the case that it often cannot be.

Thus, disambiguation of these two senses of moral verdict and moral overridingness has clear implications for specific arguments that have been put forward in normative ethics. Nonetheless, I suggested above that in current debates concerning moral verdicts and moral overridingness it is the moral standpoint sense that appears to dominate. If there is no longer a significant role for the rational standpoint sense to play, or if there is, but the moral standpoint sense is clearly the more fundamental of the two, then the dominance of the moral standpoint sense in the framing of recent debates concerning moral overridingness and moral verdicts is clearly warranted, and the significance of the disambiguation going forward will be limited. In what follows, however, I will argue that (1) it is the rational standpoint sense that provides the most straightforward explanation of the apparent conceptual connections between moral requirements and both decisive reasons and reactive attitudes, (2) it is the rational standpoint sense that is central for moral theories that distinguish distinctively moral reasons but not distinctive moral verdicts from a distinctively moral point of view, and (3) many of those who deploy the moral standpoint sense have, in the face of serious challenges, modified it to approximate more and more closely the rational standpoint sense. As a result, many structural features of rational standpoint moral verdicts that may initially have seemed problematic from within the context of the

\footnotetext{
13 See, for example, Williams' arguments on pp. 100-18 of Utilitarianism: For and Against (Cambridge: Cambridge University Press, 1973), particularly his conclusion that "It is absurd to demand of such a man ... that he should just step aside from his own projects and decision and acknowledge the decision which utilitarian calculation requires" (p. 116). For a defense of this interpretation of Williams' argument, and an argument that it generalizes quite widely, see my Beyond Consequentialism (Oxford: Oxford University Press, 2009), pp. 66-90.
} 
moral standpoint sense have on such accounts come to be features of moral standpoint moral verdicts as well. Moreover, I will suggest, in closing, that these senses should not be understood as mutually exclusive and conflicting, but as each responsive to fundamentally different questions.

Before attempting to rehabilitate the rational standpoint sense, I will first draw a clearer contrast between the two senses, beginning with the moral standpoint sense. Many philosophers take the moral standpoint sense to be the sense of moral verdicts and moral overridingness. Thus, Dale Dorsey suggests that a central question regarding moral verdicts is whether, whenever the system of moral norms "issues a requirement, this requirement is dispositive," where dispositive requirements provide "decisive reasons for $a$ to $x . "{ }^{\prime \prime}$ Moral verdicts are rational verdicts relative to a distinctive "system," perspective, point of view, or standpoint; it is a separate question whether agents have decisive reasons to do what morality in this sense requires-whether moral verdicts always yield rational verdicts simpliciter for distinctively moral reasons. If so, Claim 2 is true, and morality is moral standpoint overriding. If not, Claim 2 is false-so much the worse for the claim that morality is moral standpoint overriding. Shelly Kagan takes a given action to be morally required "if and only if it is supported by a morally decisive reason," 15 but takes it to be clear that such a reason "needs to be decisive only in comparison to the other morally acceptable reasons," such that the resulting action may well be "morally required, and yet the agent is nonetheless rationally required ... not to react in that way." 16 Moral verdicts tell us only "what people should do from the moral point of view," understood as one point of view among others. ${ }^{17}$ The question of what moral standpoint moral verdicts there are can be taken up without even considering the question of what reasons simpliciter, if any, an agent may have to do what is supported by such a moral standpoint moral verdict. Moreover, only if the answer is that all (or almost all) moral standpoint moral verdicts are reflected in decisive distinctively moral reasons simpliciter is morality moral standpoint overriding. This is what is required for the truth of

14 Dorsey, "Weak Anti-Rationalism and the Demands of Morality," pp. 4-5.

15 Shelly Kagan, The Limits of Morality (Oxford: Clarendon Press, 1989), p. 65.

16 Kagan, The Limits of Morality, p. 66.

17 Shelly Kagan, Normative Ethics (Boulder, CO: Westview, 1998), p. 10. 
Claim 2 within the moral standpoint sense of moral requirements. Similarly, Samuel Scheffler suggests that the question of overridingness is the substantive question of whether, "given an overall verdict about what one morally ought to do, one cannot rationally defy it." ${ }^{18}$ Contractualist critics of consequentialism also often operate within the moral standpoint sense. Tim Scanlon, for example, takes the overridingness question to be the moral standpoint overridingness question, the substantive question of "why a person has reason to do... what morality demands." ${ }^{.19}$ In the next section I will clarify the alternative rational standpoint sense, and begin to make the case for its rehabilitation.

\section{SECTION II: CONCEPTUAL CONNECTIONS}

Commonsense and intuition are often taken to reveal a sense of moral verdict that involves a conceptual connection to decisive reasons. It is taken to be part of the very concept of moral requirement, for example, that to judge some action to be morally required is, at least in part, to judge that there are decisive reasons to perform the action. Such a connection is invoked by Smith, with his claim that "our concept of moral requirement is the concept of a reason for action; a requirement of rationality or reasons, ${ }^{20}$ and by Sidgwick, with his claim that "we commonly think that wrong conduct is essentially irrational." ${ }^{21}$ Gibbard as well identifies such a connection as a component of our commonsense notion of moral requirement, ${ }^{22}$ as do Williams ${ }^{23}$ and Darwall. The latter stresses "conceptual connections between imputing wrong and blame, and between blame and attributing authoritative reasons." ${ }^{24}$ Each appeals to a sense of moral requirement upon which to issue such a moral verdict is, at least in part, to issue a rational verdict.

18 Samuel Scheffler, Human Morality (Oxford: Oxford University Press, 1992), p. 26.

19 T. M. Scanlon, Being Realistic About Reasons (New York: Oxford University Press, 2014), p. 1. See also p. 22: "There is therefore a question ... whether the usual ways of establishing that a form of conduct is wrong also guarantee that there are good reasons not to engage in it."

${ }^{20}$ Smith, The Moral Problem, p. 64.

21 Henry Sidgwick, The Methods of Ethics (Indianapolis: Hackett, 1981), p. 23.

22 Alan Gibbard, Wise Choices, Apt Feelings (Cambridge, MA: Harvard University Press, 1990), p. 299.

23 Bernard Williams, "Internal Reasons and the Obscurity of Blame," in Making Sense of Humanity (Cambridge: Cambridge University Press, 1995), esp. pp. 42-3.

24 Darwall, The Second-Person Standpoint, p. 94. 
Such a conceptual connection is taken to be demonstrated by many features of the discourse of moral requirement. For example, Alfred Archer and others highlight a common use of moral verdicts upon which sufficient evidence that one is not morally required to perform some action is provided by the demonstration that one has sufficiently good reasons to perform some other action. If I have sufficient reasons to do $a$, I am not morally required to do $b$ instead. ${ }^{25}$ Such claims of moral requirement are also recognized as settling the question of what we have most reason to do.

Indeed, such commonsense moral verdicts are taken to invoke a nexus of conceptual connections among (1) moral verdicts, (2) characteristic reactive attitudes such as blame and guilt, and (3) conclusive or decisive reasons of a distinctly moral sort for action. These verdicts identify actions that agents are purported to have decisive distinctively moral reasons to perform or forbear from performing, actions that it is appropriate to blame them for performing or failing to perform, ceteris paribus, and that it is appropriate for the agents themselves to experience guilt for performing or failing to perform. Reactive attitudes of blame and guilt appear to be appropriate precisely in cases in which some agent violates such a moral verdict. Demonstration that an agent had decisive-or even simply sufficient-reasons to do what she did seems to suffice, on this common understanding, to demonstrate that such reactive attitudes have no place in the case at issue. ${ }^{26}$ If I hold you blameworthy for some action, but come to agree that you in fact had perfectly good and sufficient reasons for doing what you did, reasons that would have provided me with justification for acting similarly in similar circumstances, it would seem to show a lack of understanding of the relevant concepts to nonetheless continue to maintain that you are blameworthy. As Gibbard argues, "To judge that it fully makes sense to do a thing is, in effect, not to rule out doing it oneself," but any characteristically moral reactive attitude "seems incoherent when joined to the thought 'If I am in his shoes let me do the same." "27

\footnotetext{
25 Darwall, The Second-Person Standpoint, p. 97; Sarah Stroud, "Moral Overridingness and Moral Theory," Pacific Philosophical Quarterly 79 (1998), p. 176; Archer, "Moral Rationalism Without Overridingness," pp. 107-9.

${ }^{26}$ Darwall, "Morality and Practical Reason," pp. 290-2; Gibbard, Wise Choices, Apt Feelings, p. 299; Williams, "Internal Reasons and the Obscurity of Blame," pp. 42-3.

27 Gibbard, Wise Choices, Apt Feelings, p. 299.
} 
The moral standpoint sense, upon which moral verdicts reflect decisive reasons from a distinctively moral point of view, is difficult to reconcile with commitment to such commonsense conceptual connections. For those operating within this sense, it appears to be a substantive question whether verdicts reflecting decisive reasons from a distinctly moral point of view, moral standpoint moral verdicts, always yield rational standpoint moral verdicts. Particular moral theories return a "no" answer to such a substantive question; moreover, counterexamples abound that are also often taken to support this negative answer. These examples purport to demonstrate that we often do not have decisive reasons to do what we have decisive reasons to do from the moral point of view (what is moral standpoint morally required), hence that such apparent conceptual connections in fact fail to obtain. ${ }^{28}$ Those operating within the moral standpoint sense often follow Foot in attempting to explain both why there appear to be such conceptual connections, and why such appearances are nonetheless misleading. ${ }^{29}$

By contrast, the rational standpoint sense of moral verdicts provides a straightforward explanation of such conceptual connections that confirms appearance and aligns with intuition and commonsense. A rational standpoint moral verdict just is a rational verdict for decisive reasons that are in some sense distinctively moral. For those operating within the rational standpoint sense, there appear to be such conceptual connections because there are such conceptual connections. If a judgment of moral requirement is such a judgment that there are decisive reasons to act that are distinctively moral, reasons that are in this sense overriding with respect to all other competitors, then the demonstration that the agent has good and sufficient reasons to do something else is a demonstration that such a judgment is misguided, just as our everyday practices suggest. A similar point can be made about blame.

Many philosophers who have teased out this presumptive connection between moral verdicts and decisive reasons for acting, e.g., Michael Smith and Douglas Portmore, invoke this rational standpoint sense of moral verdict. Smith emphasizes that moral verdicts are rational verdicts of a distinctive kind, such that moral verdicts "seem to be, or imply, opinions

\footnotetext{
28 Such counterexamples will be discussed in section IV.

29 See, for example, "Are Moral Considerations Overriding?" in her Virtues and Vices. I discuss her arguments further in section IV.
} 
about the reasons we have for behaving in certain ways. ${ }^{" 30}$ It is a conceptual truth, he claims, that "If agents are morally required to phi in circumstances $\mathrm{C}$ then there is a requirement of rationality or reason for all agents to phi in circumstances C." ${ }^{\text {11 }}$ Such claims are difficult to reconcile with the moral standpoint sense, but follow naturally from the rational standpoint sense. Portmore, for his part, appeals to a sense of moral requirement upon which "non-moral reasons will prevent moral reasons from generating moral requirements when they successfully counter them." ${ }^{32}$ Here Portmore invokes all of the elements of the rational standpoint sense to clarify the nature of the presumptive connections. There are distinctively moral reasons; we are morally required when such distinctively moral reasons are decisive with respect to other reasons; we are not morally required when they are not, in particular, when they are countered by sufficient non-moral reasons to act otherwise. $^{33}$

\section{SECTION III: MORAL THEORIES WITHOUT MORAL STANDPOINTS}

I have made the case that it is the rational standpoint sense of moral verdict and moral overridingness that provides the most straightforward explanation of the apparent conceptual connections between moral verdicts on the one hand, and decisive reasons and reactive attitudes on the other. In this section I will argue that it is also the fundamental sense of moral verdicts and moral overridingness for moral theories that appeal to distinctively moral reasons, but do not appeal to distinctive

30 Smith, The Moral Problem, p. 7.

31 Smith, The Moral Problem, p. 65.

32 Portmore, Commonsense Consequentialism, p. 42

33 Such an alternative understanding of moral verdicts also illuminates one source of confusion surrounding the moral demandingness debate. A moral theory is too demanding, Portmore suggests, if "it holds that agents are morally required to make sacrifices that they do not have decisive reason to make, all things considered" (Commonsense Consequentialism, p. 26). This is clearly a serious problem within the rational standpoint sense. If an action is rational standpoint morally required, then I have decisive reasons to perform it. But ex hypothesi I do not have decisive reasons. Therefore, I am not rational standpoint morally required, and a moral theory which claims that I am morally required to perform such actions is undermined. Viewed from within the moral standpoint sense, by contrast, the objection loses considerable force. If I do not have decisive reasons to do what is moral standpoint morally required, it does not follow that I am not moral standpoint morally required, hence it does not follow that a moral theory claiming that I am is straightforwardly undermined. 
moral verdicts reflecting decisive reasons from a distinctively moral point of view. Those operating exclusively within the moral standpoint sense often take all alternative moral theories to issue moral standpoint moral verdicts, verdicts from a distinctively moral point of view, and take the question of overridingness to be the question of moral standpoint overridingness: whether such moral standpoint moral verdicts are in (almost?) every case reflected in decisive distinctively moral reasons simpliciter. But if on certain theories the standpoint within the context of which distinctively moral reasons come into view, and are judged decisive with respect to other reasons, is the standpoint of reason itself, the relevant sense of moral verdict for such theories will reflect moral reasons that are decisive with respect to other reasons from this standpoint of reason-rational standpoint moral verdicts.

This would perhaps be a merely notional worry if no moral theories with such structural features were among the plausible alternatives. But examples are readily available of moral theories upon which the relevant standpoint within which distinctively moral reasons come into view is the standpoint of reason simpliciter. On one standard interpretation, Kant himself takes the standpoint from which distinctively moral reasons come into view, and from which the competing claims of distinctively moral and non-moral reasons are properly adjudicated, to be the standpoint of reason. David Brink suggests that for Kant distinctively moral reasons "apply to me in virtue of those very features that make me a responsible agent, capable of practical deliberation and subject to reasons for action." "34 Such distinctively moral reasons are distinguished by the role that they play within the standpoint of reason. In particular, categorical imperatives are distinguished from hypothetical imperatives because the latter reasons "depend upon interests and desires" while the former are "demands of pure practical reason." "It is natural on such an interpretation to understand moral requirements as rational standpoint moral verdicts generated by decisive distinctively moral reasonsdecisive pure practical reasons. It is not clear that there is even a place, on such an interpretation of Kant, for a distinctively moral standpoint, or for a sense of moral verdicts as arrived at from a distinctively moral

\footnotetext{
34 David Brink, "Kantian Rationalism," in Ethics and Practical Reason, ed. Garrett Cullity and Berys Gaut (Oxford: Clarendon Press, 1997), p. 281.

35 Brink, "Kantian Rationalism," p. 286
} 
standpoint, or for the overridingness question understood as a question about the relationship between such moral standpoint moral verdicts and decisive reasons simpliciter.

It might be argued, against any such account, that morality is distinctively impartial, and that impartiality, even for Kant, is the hallmark of a distinctively moral point of view. But this overlooks the possibility that for Kant the standpoint of reason is itself impartially structured, hence that moral reasons are not distinguished by the impartiality of the standpoint within which they come into view, but by their distinctive role within the impartial standpoint of reason. Brink advocates just such an understanding of Kant, arguing that hypothetical imperatives as well are "conditioned on interests or desires that one has that are not ruled out or screened off by the moral law." ${ }^{36}$ Even such hypothetical imperatives make their demands within an impartial deliberative structure. When categorical imperatives decisively dictate certain courses of action, an agent has decisive distinctively moral reasons to perform such actions, and they are rational standpoint morally required. When hypothetical imperatives alone dictate certain courses of action, such actions are not morally required. Both hypothetical and categorical requirements of reason come into view within the same fundamentally impartial standpoint, but it is the standpoint of reason, and the resulting moral verdicts are rational standpoint moral verdicts.

Barbara Herman develops a somewhat different interpretation of Kant that is nonetheless similar in these relevant respects. ${ }^{37}$ On the Kantian account, Herman argues, desires "normally contain... a conception of the object's value... as determined by its fit with other things valued, and as its satisfaction ... comports with the principles of practical reason." "38 To cite such desires or their objects is to invoke paradigmatically "partial" reasons, but for Kant such reasons have been normalized within the impartially structured space of practical reason. The rational agent's impartially structured "deliberative field" normalizes affective experiences such that the value of the objects of our desires reflects whether their satisfaction comports with the principles of practical

\footnotetext{
36 Brink, "Kantian Rationalism," p. 286.

37 See in particular her "Making Room for Character," in her Moral Literacy (Cambridge: Cambridge University Press, 2007), pp. 1-28.

38 Herman, "Making Room for Character," p. 17.
} 
reason, most fundamentally of pure practical reason. ${ }^{39}$ On such interpretations of Kant moral verdicts are arrived at from an impartial point of view, but the impartial point of view is the standpoint of reason, and such moral verdicts are rational verdicts for distinctively moral reasons (rational standpoint moral verdicts) that come into view within this impartially structured standpoint of reason. When reasons that are not distinctively moral are sufficient or decisive, the agent is not morally required to act. There is clearly a place, on such an interpretation of Kant, for distinctively moral reasons, rational standpoint moral verdicts, and rational standpoint overridingness. But what place is there for moral standpoint moral verdicts and moral standpoint overridingness? Stephen Darwall points out that although for Kant we have moral reasons to donate to the poor, Kant "does not say, however, that the moral reasons supporting donation... invariably outweigh the reasons for not giving." ${ }^{40}$ In cases in which they do not outweigh, the agent is not morally required to donate because such a course of action is not decisively favored by reasons simpliciter that are distinctively moral. It is the rational standpoint sense of moral requirement that is relevant; moreover, there would appear to be no sense on such an account in which donating to the poor is morally (but not rationally) required.

Adam Smith's Enlightenment take on virtue ethics invites an interpretation that is similar in these respects. The standpoint of reasonableness — of prudence, beneficence, temperance, courage, justice, etc. - is the standpoint of the "impartial spectator." ${ }^{\text {"1 }}$ Reasonable persons guard against the distorting effects of self-love by developing certain rules that reflect virtues of justice and beneficence, rules of morality that typically provide reasons for the reasonable person to act that are decisive with respect to competing reasons. ${ }^{42}$ For reasonable persons such moral

\footnotetext{
39 Herman develops this "device" of a deliberative field in "Making Room for Character," sec. IV.

40 Darwall, "Morality and Practical Reason,” p. 286.

41 See Smith's discussion of the impartial spectator as establishing the standard of reasonableness in The Theory of Moral Sentiments (New York: Dover, 2006), Part I, Section I, chapters III and IV, and Section II, chapters III and IV.

${ }^{42}$ See Smith's discussion of moral rules, The Theory of Moral Sentiments, Part III, chapters II-IV. Of particular relevance is his argument that although such rules are "commonly cited as the ultimate foundation of what is just and unjust," this is misleading. They are in fact formed via the standpoint of the impartial spectator "from the experience we have had of the effects which actions of all different kinds naturally produce upon us" (p. 154).
} 
rules typically generate rational standpoint moral verdicts, but the standpoint from which such reasons come into view as providing the distinctively moral reasons that they do is fundamentally the standpoint that structures all of the sentiments of the reasonable person, the standpoint of Smith's impartial spectator.

For each of these theories moral requirements reflect decisive reasons that are distinctively moral. It is from the standpoint of reasons/the reasonable person that it becomes clear not only which reasons are distinctively moral, but that in certain cases such distinctively moral reasons are decisive with respect to other reasons. Agents are in such cases rational standpoint morally required to act. A related point can be made about many Hobbesian accounts as well. For a Hobbesian such as Gauthier "the point of morality is surely to override preference," ${ }^{43}$ to generate rational standpoint moral verdicts that reflect decisive distinctively moral reasons to act. It is the rational point of view, understood as the point of view of preference maximization, that generates such distinctively moral reasons. These distinctively moral reasons yield rational standpoint moral verdicts that prohibit a rational agent from acting "to realize his or her most preferred state of affairs." 44

These are three radically different approaches to moral theorizing, but each is amenable to an interpretation upon which distinctively moral reasons come into view fundamentally from the standpoint of reason (Kant), the reasonable (Smith), or the rational (Gauthier). Morality requires a particular course of action, on such accounts, when the reasons simpliciter that are distinctively moral, e.g., the categorical, unconditional reasons of Kant, the reasons that constrain reasons for Gauthier, and the reasons provided by moral rules reflecting the virtues of justice and beneficence for Smith, provide decisive reasons simpliciter in favor of some particular course of action. The moral standpoint sense of moral verdict and moral overridingness need not even come into view.

The point is not to advocate any of these moral theories, or these interpretations of moral theories, over alternatives. But their availability as alternatives demonstrates the extent to which framing questions of moral verdicts and moral overridingness exclusively within the context

\footnotetext{
43 David Gauthier, "Bargaining Our Way into Morality,” Philosophic Exchange 10 (1979), p. 15 .

${ }^{44}$ Gauthier, "Bargaining Our Way into Morality,” p. 15.
} 
of the moral standpoint sense skews the debate among alternative views. Such a framework rules out such moral theories ex ante, or shoehorns them into a structure that systematically misrepresents the nature of the alternatives they provide to moral theories that do appeal to moral standpoint moral verdicts from a distinctively moral point of view. Moreover, to put forward the moral standpoint sense as the sense co-opts the concepts of moral verdict and moral overridingness such that such moral theories cannot even be characterized as offering accounts of rational standpoint moral verdicts and rational standpoint overridingness.

\section{SECTION IV: THE RATIONAL STANDPOINT SENSE WITHIN} THE MORAL STANDPOINT SENSE

In this section I will demonstrate that structural features characteristic of the rational standpoint sense play a central role even in accounts that purport to invoke only the contrasting moral standpoint sense of moral verdict and moral overridingness. To see why, notice first how the rational standpoint sense accommodates the standard objections to moral overridingness that arise for those who deploy the moral standpoint sense. Examples of such standard objections abound: An agent arrives correctly at a moral standpoint moral verdict to promote the overall good, but some other course of action, which only promotes slightly less overall good, is much better for her or for her children. Alternatively, an agent's keeping his promised appointment is decisively supported by reasons from the moral point of view, but he finds that he must risk serious physical harm (due to illness) or forgo a tremendous opportunity for personal benefit (phone call with a job offer) to keep his promise. In general, if only certain reasons are taken into account from the moral point of view, and only in certain respects, then, as Sarah Stroud argues, "certain considerations which are genuine reasons have been left out of the moral calculus," and "we will get failures of overridingness when something which clearly has force from the perspective of reasons in general is not taken into account in reaching a moral verdict." ${ }^{25}$

45 Stroud, "Moral Overridingness and Moral Theory," p. 180. 
Such failures of overridingness can indeed appear difficult to avoid when operating within the moral standpoint sense, and these cases highlight the difficulties. But consider such cases within the context of the rational standpoint sense. Rational standpoint moral verdicts result, and morality is rational standpoint overriding, in cases in which distinctively moral reasons provide decisive reasons simpliciter. But these purported counterexamples are precisely cases in which it is held that distinctively moral reasons fail to be decisive. For those who deploy the rational standpoint sense, such piling up of non-moral considerations does not show that the agent has sufficient reasons to do something other than what morality requires, it shows that moral considerations are not in such cases decisive, hence do not result in moral requirements. If nonmoral reasons of personal benefit are sufficiently weighty, for example, then there is not a rational standpoint moral requirement to promote the overall good because the relevant distinctively moral reasons to do so are not rational standpoint overriding.

Many advocates of the moral standpoint sense readily allow that a plausible moral theory must accommodate some such cases. Moral theories that fail to do so, they allow, are too demanding or alienating to provide plausible alternatives. These cases are often accommodated within the moral standpoint sense of moral verdict by allowing that at least some non-moral reasons are appropriately taken into account noninstrumentally within the distinctively moral point of view. Philippa Foot, herself no advocate of moral standpoint overridingness, nonetheless accounts for its apparent appeal as due in large part to the fact that unlike the standpoint of etiquette, morality provides a distinctively inclusive standpoint such that many exceptions reflecting non-moral considerations are included "within morality:"

Moral rules are not taught as rigid rules that it is sometimes right to ignore; rather we teach that it is sometimes morally permissible to tell lies (social lies), break promises... and refuse help (where the cost of giving it would be, as we say, disproportionate). ${ }^{46}$

\footnotetext{
46 Foot, "Are Moral Considerations Overriding?" in Virtues and Vices, p. 187. Only in her subsequent statement, that such exceptions occur within morality, does it become clear that she is operating within the moral standpoint sense.
} 
The suggestion is that certain non-moral reasons are appropriately taken into account along with distinctively moral reasons in arriving at moral verdicts from the moral point of view. Morality only issues even moral standpoint moral verdicts, on such accounts, when such non-moral reasons are not sufficiently weighty from the moral point of view. Such an approach is seen as well in Scheffler's argument that personal reasons are comprehended within the standpoint from which it is determined what, if anything, morality requires. If such non-moral considerations are sufficiently weighty from the moral point of view, morality does not yield even a moral standpoint moral requirement. ${ }^{47}$ Neither Foot nor Scheffler defends the substantive claim that morality is moral standpoint overriding, but each accounts for the apparent appeal of overridingness in part by highlighting the distinctive nature of the point of view from which distinctively moral reasons come into view, emphasizing that it comprehends certain non-moral reasons noninstrumentally. Moral verdicts only issue from such a point of view in cases in which distinctively moral reasons are decisive with respect to non-moral reasons within this more comprehensive and inclusive moral point of view.

Philosophers who operate within the moral standpoint sense, but who are more sympathetic to the claim that morality is moral standpoint overriding, emphasize even more the distinctiveness of the moral point of view, in particular the comprehensiveness and inclusiveness of this point of view. Thus, Seana Shiffrin argues that the moral point of view is "a package of a special type of reasons and a special way of relating them to all the other sorts": ${ }^{48}$

On this picture, to take up the moral point of view is to see and evaluate a whole range of reasons from a distinctive, objective point of view ... It both introduces certain distinctive considerations as having reason-giving force and offers a methodology for regarding and resolving conflicts with competing, different sorts of considerations. ${ }^{49}$

\footnotetext{
47 Samuel Scheffler, The Rejection of Consequentialism (Oxford: Oxford University Press, 1982).

48 Seana Shiffrin, "Moral Overridingness and Moral Subjectivism," Ethics 109 (July 1999), p. 791 .

49 Shiffrin, "Moral Overridingness and Moral Subjectivism," p. 788.
} 
On such an understanding of the moral point of view, the considerations cited in alleged counterexamples as competing with reasons generated from the moral point of view are themselves taken into account noninstrumentally from the moral point of view in the determination of what, if anything, is moral standpoint morally required or forbidden. ${ }^{50}$ Similarly, Stroud maintains that from the moral point of view, properly understood, "considerations which might otherwise have grounded a moral requirement do not do so when there are strong personal costs on the other side. ${ }^{" 51}$ Such philosophers thus argue that although there is a distinctively moral point of view, and there are distinctive moral verdicts reflecting decisive reasons from such a point of view, it is a distinctively comprehensive and inclusive point of view. It non-instrumentally comprehends the legitimate reasons provided by certain non-moral considerations in the determination of what, if anything, is moral standpoint morally required. If such other non-moral considerations are sufficiently weighty from the moral point of view, morality simply does not yield a moral standpoint moral verdict. Such defenders of moral standpoint overridingness see the purported counterexamples not as evidence that morality is not overriding, but as evidence of the impoverished nature of the account of the standpoint from which moral verdicts issue. ${ }^{52}$

Thus, many philosophers working within the moral standpoint account, both critics and defenders of moral standpoint overridingness, maintain that the distinctively moral point of view from which distinctively moral reasons come into view takes into account non-moral reasons, appreciating the intrinsic value that they reflect. Moral standpoint moral verdicts result only if the distinctively moral reasons that come into view from such a standpoint are decisive with respect to such

50 Shiffrin: "On this view, morality's distinctiveness issues, partly, from its attempt to offer a superfunction of reasons" ("Moral Overridingness and Moral Subjectivism," p. 791).

51 Stroud, "Moral Overridingness and Moral Theory," p. 184. Shiffrin makes a similar point in her discussion of aesthetic considerations ("Moral Overridingness and Moral Subjectivism," p. 791).

52 Shiffrin notes that moral considerations can also be taken into account from the prudential standpoint, but takes there to be a crucial difference: "Prudence may acknowledge the significance of moral concerns but only for the instrumental value that moral obedience may have for achieving one's interest." By contrast, "Morality... sees concerns emanating from the personal point of view as having a certain intrinsic value and attempts to assess what their real value is and how moral considerations relate to them" ("Moral Overridingness and Moral Subjectivism," p. 790). 
non-moral reasons from the moral point of view. These respects in which the moral point of view is distinctive, moreover, generate a simulacrum of rational standpoint moral verdicts within the context of moral standpoint moral verdicts: moral standpoint moral verdicts are not just rational verdicts from the distinctively moral point of view, but rational verdicts for decisive distinctively moral reasons from such a distinctively moral point of view. The question of moral standpoint overridingness, on such accounts, is whether such rational verdicts for distinctively moral reasons from the moral point of view (hence still moral standpoint moral verdicts) also yield rational standpoint moral verdicts, rational verdicts for decisive reasons simpliciter that are in some sense distinctively moral.

Those who are sympathetic to moral standpoint overridingness emphasize the inclusion of virtually all reasons simpliciter within the moral point of view, such that it is difficult to find significant space between the moral standpoint, thus understood, and the standpoint of reason simpliciter. Morality, on such accounts, is moral standpoint overriding because rational verdicts for distinctively moral reasons from the moral point of view—-moral standpoint moral verdicts—are, de facto, rational verdicts for distinctively moral reasons from the standpoint of reason simpliciter-rational standpoint moral verdicts. Those who reject moral standpoint overridingness within such a sophisticated moral standpoint maintain that although the moral point of view includes non-moral reasons, and only yields moral verdicts when distinctively moral reasons are decisive with respect to such non-moral reasons, nonetheless the reasons or weight of reasons from the standpoint of reason diverge (or at least can diverge) from the reasons or weight of reasons from the distinctively moral point of view.

But if on such accounts (1) the point of view from which distinctively moral reasons come into view is a distinctively comprehensive point of view, and (2) it only yields verdicts of the morally relevant sort if distinctively moral reasons outweigh other relevant non-moral reason from that point of view, and (3) it non-instrumentally includes nonmoral as well as moral reasons along with an account of how they relate to each other, then it seems clear that in the quest for greater plausibility, such sophisticated accounts operating within the moral standpoint sense have taken on more and more of the features characteristic of the rational standpoint sense. Moral standpoint moral verdicts become more plausible as they approach rational standpoint moral verdicts, and moral 
standpoint overridingness, at the limit, becomes indistinguishable from rational standpoint overridingness. The limit case of such a process of sophistication is a standpoint that comprehends all reasons, and gives them the weight that they have as reasons simpliciter, yielding moral standpoint moral verdicts only when distinctively moral reasons are decisive. But such a limit case for moral standpoint moral verdicts would simply be an account of rational standpoint moral verdicts, and on such an account moral standpoint overridingness would simply be rational standpoint overridingness.

\section{SECTION V: THE INTERPLAY OF THE TWO SENSES}

I have argued that although the moral standpoint sense dominates philosophical debates concerning moral verdicts and moral overridingness, it is the rational standpoint sense that most straightforwardly accounts for the various intuitive conceptual connections between moral requirement and decisive reasons for action. This rational standpoint sense, moreover, is untroubled by alleged counterexamples to moral overridingness that dominate the discussions of those operating within the moral standpoint sense, and it is clearly the fundamental sense of moral verdicts and moral overridingness for moral theories that recognize a role for distinctively moral reasons, but not a fundamental role for a distinctive class of moral verdicts that reflect only the decisiveness of reasons from a distinctively moral point of view. Finally, a simulacrum of rational standpoint moral verdicts is articulated within the moral point of view by more developed accounts that deploy the moral standpoint sense, and the limit case for such development would appear to be a complete alignment of the moral standpoint sense with the rational standpoint sense.

I have made the case that those who operate exclusively within the context of only one of these senses, and who assume that others do as well, are talking past rather than engaging with many of their critics. Such an assumption that either of these is the sense of moral verdicts and moral overridingness within the context of which the claims of all moral theories and all moral disputes are to be interpreted profoundly distorts the debate from the outset. I have also suggested in the discussion of Singer that certain arguments can easily trade upon the conflation of aspects of these two senses. But nothing that I have argued so far makes 
the case that these senses cannot both be incorporated into one and the same moral theory. In closing, I will make an initial effort to locate these distinct senses with respect to each other in light of the insights gained in the process of disambiguating them.

We have already seen that each is frequently put forward as the sense of moral verdicts and moral overridingness. They are treated as competing and mutually exclusive alternatives. My suggestion is that there is instead an important division of theoretical labor reflected in these two senses, and that the assumption of mutual exclusivity and the homonymous terminology make it difficult to recognize that each sense is responsive to a fundamentally different question. The question of when distinctively moral reasons are rationally authoritative-when moral reasons are decisive reasons-is of the first importance for rational agents. It is thus not at all surprising that one of our central senses of moral verdicts, the rational standpoint sense, identifies the acts and act types supported, at least ceteris paribus, by decisive distinctively moral reasons. Nor is it surprising that such an understanding is deeply embedded in our everyday moral practices. What we want to know, in our interactions with each other, is which acts and act types we have decisive moral reasons to perform - which actions are rational standpoint morally required, supported by rational standpoint overriding moral reasons. My suggestion is that this central question, to which the rational standpoint sense is directly responsive, is relevant for almost any moral theory, regardless of whether or not the theory also appeals to distinctive moral standpoint moral verdicts from a distinctively moral point of view.

For moral theories that do appeal to a distinctively moral point of view and a distinctive class of verdicts that reflect decisive reasons from such a point of view, the question of when some action or act type is moral standpoint morally required will arise alongside that of when some action or act type is rational standpoint morally required, as will the question of the relationship between such requirements. It is crucial not to conflate the question central to the rational standpoint sense, the question of what acts and act types are required of rational agents by decisive distinctively moral reasons, with the moral standpoint sense questions that are relevant on some moral theories, questions of what agents have decisive reasons to do from the moral point of view, and what the relationship is between such decisive reasonableness from a 
distinctively moral point of view and decisive reasonableness simpliciter for distinctively moral reasons. ${ }^{53}$

The question of moral standpoint overridingness, for example, is the question of whether the moral standpoint moral verdicts that reflect decisive reasons from the moral point of view are always reflected in rational standpoint moral verdicts reflecting decisive reasons simpliciter that are distinctively moral. Even if they are not, and morality is not on such an account moral standpoint overriding, this still leaves remaining the question of when such moral standpoint moral verdicts are reflected in rational standpoint moral verdicts: When are rational agents rational standpoint morally required to do what we are moral standpoint morally required to do, such that rational agents have rational standpoint overriding moral reasons to do what is moral standpoint morally required? Consider, in this regard, Susan Wolf's closing argument in "Moral Saints." 54 She offers a characterization of moral theories from within the moral standpoint sense. There is a distinctively moral point of view which "demands expression in one's actions and in the form of one's practical deliberations." 55 This moral point of view is a source of distinctively moral reasons that we are "obliged to take up and express in our actions." But we may also have "positive, good reasons" that come into view from the "point of view of individual perfection." 56 Taking into account these other non-moral reasons, she argues, challenges the meta-moral assumption that "it is always better to be morally better" 57 that morality is moral standpoint overriding. Nonetheless, these moral reasons that come into view from the distinctively moral point of view provide reasons simpliciter that every agent is obligated to take into account in deciding what she has the best reasons simpliciter to do. When such distinctively moral reasons are decisive, it will be better simpliciter to do what is "morally better." This question of when it is better simpliciter to do what is morally better is the question of when morality is rational standpoint overriding, such that agents are rational

\footnotetext{
53 For a perceptive discussion of such questions see Karl Schafer, "The Modesty of the Moral Point of View," in Weighing Reasons, ed. E. Lord and B. Maguire (Oxford: Oxford University Press, forthcoming).

54 Susan Wolf, "Moral Saints," The Journal of Philosophy 79 (August 1982): 419-39.

55 Wolf, "Moral Saints," p. 437.

56 Wolf, "Moral Saints," pp. 436 and 437.

57 Wolf, "Moral Saints," p. 438
} 
standpoint morally required to act. On Wolf's account agents do not always have decisive reasons to do what they have decisive reasons to do from the moral point of view, but they do sometimes have decisive reasons simpliciter that are distinctively moral (are rational standpoint morally required) to perform certain actions or types of actions.

In sum, my suggestion is that the question central to the rational standpoint sense of moral verdict, the question so deeply embedded in our moral practices, is the question of what, if anything, morality demands of us as rational agents-what acts and act types we have decisive distinctively moral reasons to perform. This question is relevant for almost any moral theory, regardless of whether or not it appeals to distinctive moral standpoint moral verdicts from a distinctively moral point of view. Those who appeal to the rational standpoint sense of moral verdicts deploy this intuitive use of moral verdict language, the sense that reflects rationally authoritative moral reasons for some action or act type. On theories that recognize in addition a distinctively moral point of view and a distinctive sense of moral verdict that reflects decisive reasons from such a point of view, an obvious question will be whether such moral standpoint moral verdicts are always reflected in rational standpoint moral verdicts (moral standpoint overridingness), or only sometimes are. Theories that articulate accounts of moral standpoint moral verdicts, in short, should not be understood as challenging the role of rational standpoint moral verdicts, but, properly understood, as raising additional questions regarding the relationship between two senses of verdicts and overridingness that reflect different fundamental questions.

My task here has been to distinguish the two very different senses of moral verdicts and moral overridingness that are invoked both in our moral practices and in our moral theories, and to make the case that the assumption that one or the other is the sense that is or ought to be at work in moral theory severely distorts both central debates in moral theory and alternative positions within such debates. These are not rival and mutually exclusive senses of verdicts and overridingness; they are distinctive senses that are responsive to different fundamental questions about morality and the role of morality within reason. For theories that appeal to a distinctively moral point of view and distinctive moral verdicts reflecting decisive reasons relative to such a point of view, an adequate account must take up the relationship between these two very different senses of moral verdict and moral overridingness, and must be 
clear about the answers it provides to the very different questions to which each sense is responsive.

\section{Acknowledgments}

Much thanks to participants in the Claremont Colleges Works in Progress Group and the 2015 Arizona Workshop in Normative Ethics for extremely helpful discussions of earlier drafts of this paper. I have benefited in particular from conversations with Sarah Stroud, Douglas Portmore, Stephen Darwall, Susan Wolf, Barry Maguire, Dustin Locke, Alex Rajczi, Julie Tannenbaum, Andrew Schroeder, Peter Thielke, and Rivka Weinberg. I have also benefited from insightful feedback from two anonymous referees. Special thanks to Mark Timmons for running his superb workshop every year and editing the resulting volume. 